\title{
Atrioventricular Node Reentrant Tachycardia (AVNRT) after mitral valvuloplasty during cardiac rehabilitation
}

\author{
Tachicardia da rientro del nodo Atrioventricolare \\ in paziente già sottoposto a valvuloplastica mitralica \\ ed insorta nel corso di riabilitazione cardiologica
}

\author{
Luca Fallavollita1, Elpidio Santillo1, Luciano Marini1, Fabrizio Balestrini1
}

\begin{abstract}
Atrioventricular Node Reentrant Tachycardia (AVNRT) after mitral valvuloplasty during cardiac rehabilitation. L. Fallavollita, E. Santillo, L. Marini, F. Balestrini.

We descrive a patient who presents palpitations during cardiac rehabilitation after mitral valvuloplasty. ECG showed regular narrow QRS tachycardia compatible with Atrioventricular Node Reentrant Tachycardia. After slow
\end{abstract}

pathway radiofrequency catheter ablation, the patient completed the rehabilitation program remained tachycardia and palpitations-free.

Keywords: Atrioventricular node reentrant tachycardia, radiofrequency catheter ablation, cardiac rehabilitation.

Monaldi Arch Chest Dis 2012; 78: 212-213.

1 Unità Operativa Cardiologia Riabilitativa - INRCA - Fermo

Corresponding author: Dott. Luca Fallavollita, Istituto di Ricerca a carattere scientfico INRCA sede Fermo, c.da Mossa. E-mail address:l.fallavollita@inrca.it

\section{Introduction}

The Atrioventricular Node Reentrant Tachycardia (AVNRT) is most common cause of regular narrow QRS tachycardia. The type "slow-fast" reentry circuit is found in $90 \%$ of patient with AVNRT. Ablation of the slow pathway is a simple procedure used to cure AVNRT. The current case report describes a patient with typical AVNRT which occurred during cardiac rehabilitation after mitral valvuloplasty. After slow pathway radiofrequency catheter ablation, no reentrant tachycardias were inducibile. The patient remained free of tachycardia and palpitatios.

\section{Case report}

In febrary 2012 came to our observation to perform cardiac rehabilitation, after being subjected to mitral valvuloplasty with quadrangular resection of posterior leaflet and implantation of ring $n^{\circ} 35$, because of severe mitral regurgitation in prolapse of posterior leaflet. The patient was treated with verapamil $240 \mathrm{mg} / \mathrm{die}$.

At the time of clinic evaluation at our Institute, the patient was asymptomatic. An objective chest examination revealed the presence of a continuos murmur 2/6 Levine at the apex. The 12-lead electrocardiogram was normal. As a regular practice at our Center, an ergometric test was carried out on cicloergometer which no revealed test symptons not even electrocardiographic alterations. The patient also performed a transthoracic echocardiogram which revealed mild mitral regurgitation; normal position of valvular ring; left ventricle within normal limits; aortic root and left atrium within normal limits, normal and regional function of LV; ejection fraction 55\%; mild diastolic dysfunction; right chambers within normal limits for dimension and function; no sign of pulmonary hypertension; no pericardial effusion.

The patient was placed in the cardiac rehabilitation program. The patient was asked to participate in one-hour monitoring exercise, which consisted of 10 minute of warm-up, 40 minutes of main exercise in cicloergometer and 10 minutes of cool-down in the hospital three times per week for a total five weeks (15 sessions). The exercise intensity was calculated using the Karvonen formula [1]. Heart rate and ECG were monitored real-time during the cardiac rehabilitation. The exercise intensity was limites to the target heart rate of $60 \%$ to $80 \%$ based on Karvonen formula [2]. At the end of third session, the patient reported palpitations. ECG showed tachycardia a narrow QRS complex with heart rate of 156 beat $/ \mathrm{min}$ and $\mathrm{PR}<\mathrm{RP}$ (Figure 1) suggesting atrioventricular nodal re-entrant tachycardia.

The tachycardia was refractory to stimulation of vagal maneuvres (carotid sinus massage); conversely, was immediately terminated by a single dose of adenosine $6 \mathrm{mg} \mathrm{IV}$, and sinus rhytm with heart rate of 84 beats/min was restored (Figure 2).

An electrophysiological study was performed for further evaluation at Clinical Cardiology of 


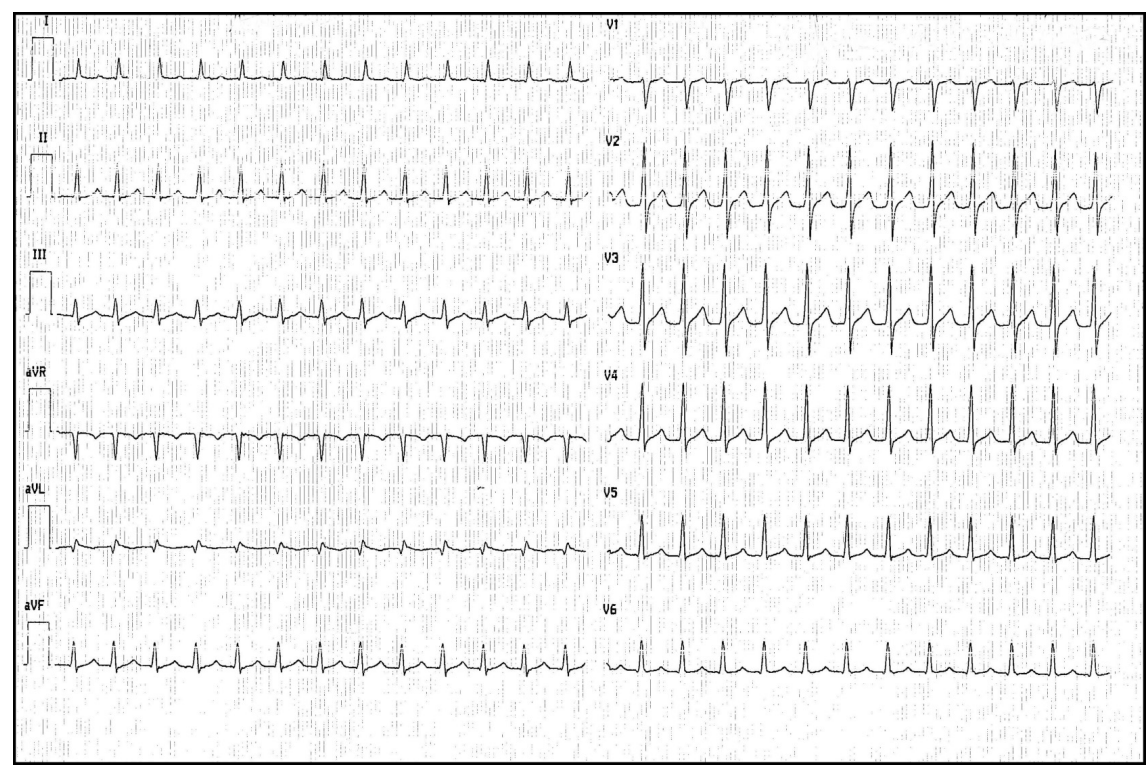

Figure 1. - Tachycardia a narrow QRS complex with HR 156 beats/min.

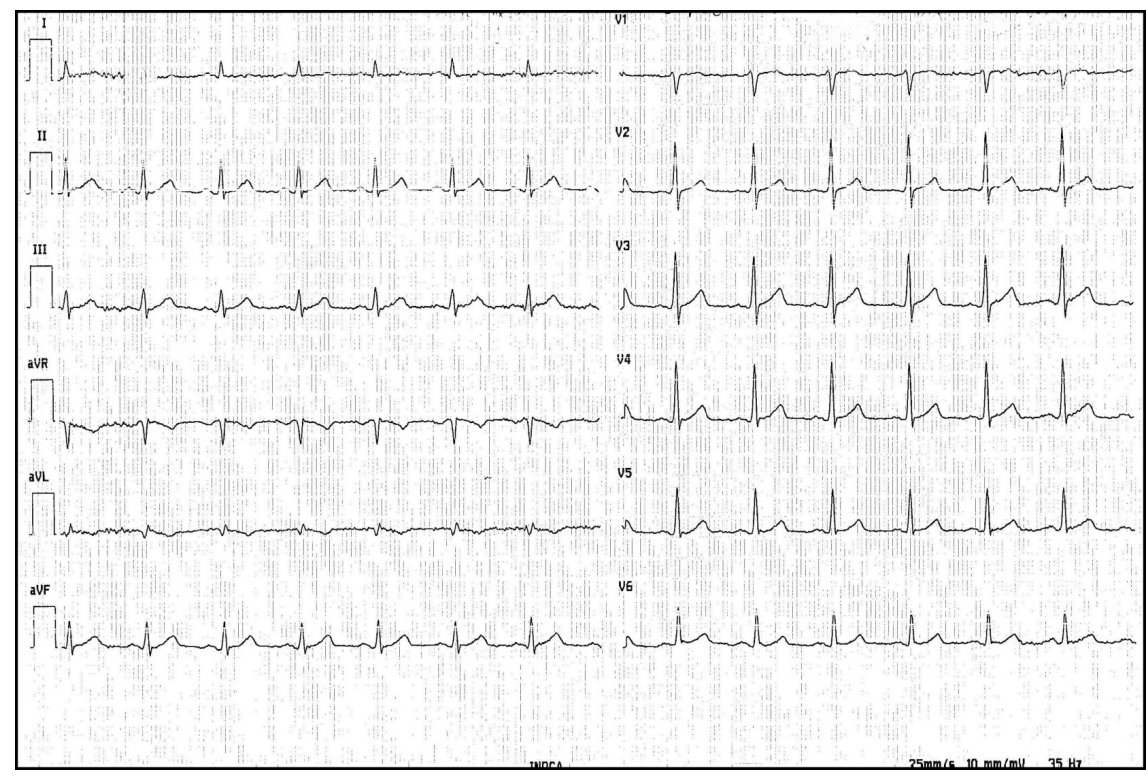

Figure 2. - Tsinus rhytm with HR 84 beats/min after adenosine IV.

Ancona Hospital. Verapamil had been discontinued for one week. This study showed a typical form of slow-fast re-entry AV tachycardia with a cycle length of $355 \mathrm{msec}$. Radiofrequency catheter ablation of with standard energy measures was performed and the slow pathway (SP) was successfully ablated in single application. After the selective SP ablation, no tachycardia was inducible. Atrio-Hisian and His-Ventricular measurements were $40 \mathrm{msec}$ and $40 \mathrm{msec}$, respectively. The patient was discharged and has completed the rehabilitation program remained tachycardia and palpitations-free.

\section{Discussion}

The Atrio-ventricular nodal re-entrant tachycardia (AVNRT) is a relatively common cause of regular narrow QRS tachycardia [3]. In AVNRT there are two functionally and anatomically different distinct patways in the atrio-ventricular node, with different conduction velocities and different refractory periods [4]. The fast pathways form the usual physiological conduction axis during sinus rhythm. In the typical type of AV nodal reentry, secondary to premature atrial beat, the slow pathway conducts in the anterograde direction and the fast pathway in the retrograde direction. Thus the circuit is created [4]. The type "slowfast" is found in $90 \%$ of patients with AVNRT [4].

We describe a case of typical AVNRT insurgent during cardiac rehabilitation after mitral valvuloplasty. Radiofrequency ablation of SP has been performed successfully. We hypothesized that the recent intervention in minitoracotomia with the formation of atrial scar may have been a factor favoring the onset of atrial trigger (atrial premature beats). Furthermore, we believe that vagal hypertonia secondary to training, may have been a factor modulating the genesis of AVNRT by means of reduction of the atrial refractory periods.

\section{Riassunto}

Viene descritto il caso di un paziente che ha riferito palpitazioni nel corso della riabilitazione cardiologica eseguita a seguito di valvuloplastica mitralica. L'ECG ha mostrato una tachicardia a QRS stretti e regolari compatibile con Tachicardia da rientro del nodo Atrioventricolare. Dopo aver eseguito l'ablazione a radiofrequenza tramite catetere, il paziente ha completato la riabilitaizione cardiologica ed è rimasto libero da recidive di tachicardia e palpitazioni.

\section{References}

1. Karvonen MJ, Kentala E, Mustala O. The effect of training on heart rate; a longitudinal study. Ann Med Exp Biol Fenn 1957; 35: 307-315.

2. Chul Kim, Byung Ok Kim, Kil-Byung Lim, Young Joo Kim, Yong Bum Park. The effect of power-walking in phase 2 cardiac rehabilitation program. Ann Rehabil Med 2012; 36(1):133-140.

3. Akhtar M, Jazayeri MR, Sra J et al. Atrioventricular nodal reentry. Clinical, electrophysiologic and therapeutic considerations. Circulation 1993; 88:282-95.

4. Esberger D, Jones S, Morris F. ABC of clinical electrocardiography. Junctional tachycardias. BMJ 2002; 324: 662-5. 